\title{
$\mathrm{TV}$ 애니메이션 '똑똑박사 에디' 의 \\ 스토리텔링 요소와 수학내용 분석
}

김지영 ${ }^{*}$

${ }^{1}$ 호남대학교 유아교육과

\section{An Analysis of Storytelling Factors and Mathematics Contents of 'Eddy, the Clever Fox' on TV Animation}

\author{
Ji-Young Kim $^{1^{*}}$ \\ ${ }^{1}$ Department of Early Childhood Education, Honam University
}

요 약 본 연구는 TV 애니메이션 ‘똑똑박사 에디'의 스토리텔링 요소와 수학내용을 분석하는데 목적이 있다. 선행 연구와 문헌을 토대로 설정한 분석기준에 따라 시나리오와 애니메이션을 보면서 내용분석과 빈도분석을 실시하였다. 연구결과를 제시하면 첫째, 의인화된 11 명의 동물이 등장인물로 나오며, 에디는 주인공으로서 문제해결자의 역할을 담당한다. 등장인물의 말, 행동, 사고양식은 전조작기 유아의 수준으로 묘사된다. 눈 덮인 숲 속 마을을 배경으로 일 상적이고 평범한 스토리가 진행되며, 중심서사는 있으나 이야기는 플롯의 형식으로 구성되어 있지 않다. 이야기의 주 내용은 수학내용을 다루고 있으며, 에피소드는 대화, 노래, 나레이션을 통해 진행된다. 둘째, 애니메이션에서는 1 회당 평균 23회의 수학내용을 다루고 있으며, 수감각, 기하, 측정, 자료분석과 확률, 규칙성의 순으로 나타났다. 이로서 '똑 똑박사 에디'는 에듀테인먼트로서의 가치가 있는 작품으로 평가할 수 있다.

\begin{abstract}
The purpose of this study is to analyze storytelling factors and mathematics contents of 'Eddy, the clever fox' on TV animation. The scenario and animation were analyzed according as criterion based on relevant materials. The results are as follows: First, Characters are 11 animals, Eddy is a problem solver. An ordinary story happens in the snow-covered woodland village. There is no story plot. And the story consists dialogue, song and narration. Second, mathematics contents in the animation appear in order number sense, geometry, measurement, data analysis and probability, pattern. So 'Eddy, the clever fox' is valuable as edutainment.
\end{abstract}

Key Words : Mathematics contents, Storytelling factors, TV animation

\section{1. 서론}

유아들은 어렸을 때부터 일상생활 속에서 자연스럽게 전자미디어를 접하게 된다. 이 중에서 TV는 유아 주변에 서 가장 손쉽게 접할 수 있는 매체이며, 관찰과 모방을 통해 학습이 이루어지는 도구이다. TV 프로그램은 다양 하지만 유아가 가장 선호하며 좋아하는 방송은 애니메이 션이며[1], 현재 EBS 유아.어린이용 방송 중에서 애니매 이션은 과반수 이상(62.3\%)을 차지한 것으로 조사되었다
[2].

애니메이션은 시각적 이미지와 텍스트의 서술성, 음악 이 상보적으로 융합되어 있는 예술이다[3]. 시청자에게 내용을 전달하기 위해서 색, 소리, 음악, 움직임, 언어를 활용하여 다양한 이미지를 결합한 양식이다. 애니메이션 은 등장인물의 움직임, 입체적이면서 아름다운 이미지 변 화, 음향으로 극적인 장면을 연출하여 유아의 흥미를 끌 며 몰입하게 만든다.

애니메이션은 유아에게 풍부한 상상력과 감성을 제공

이 논문은 2012년도 호남대학교 학술연구비 지원을 받아 연구되었음.

*Corresponding Author : Ji-Young Kim(Honam Univ.)

Tel: +82-62-940-5531 email: kjy4549@hanmail.net

Received December 20, 2013 Revised (1st January 7, 2014, 2nd January 14, 2014)

Accepted February 5, 2014 
하며, 흥미를 유발시키고, 인지적·정서적 발달을 도와주 는 에듀테인먼트로서의 역할을 할 수 있다[4]. 에듀테인 먼트(edutainment)란 교육(education)과 놀이(entertainment)의 합성어로, 오락적인 흥미를 반영한 교육 콘텐츠를 의미한 다[5]. 사용자가 놀이를 즐기는 과정에서 교육의 효과를 얻을 수 있도록 고안된 콘텐츠로서[4], 자발적이고 자기 주도적인 자세로 '보다 즐겁고 재미있게 학습하기'의 방 법이 가능하다. 에듀테인먼트 콘텐츠의 성공 열쇠는 교육 과 흥미간의 적절한 균형 유지이다. 유아들은 에듀테인먼 트 애니메이션을 접하면서 콘텐츠에 내재된 교육 내용에 대한 학습이 이루어진다. 유아에게 의미있는 교육이 되기 위해서는 학습내용은 스토리에 자연스럽게 흡수되어 반 복적으로 노출되어야 한다. 또한, 유아들이 재미를 느낄 수 있는 흥미 요소도 중요한 요인이다. 유아들이 좋아하 는 캐릭터, 흥미진진한 스토리와 음향은 관심을 끌기에 충분하다. 유아는 애니메이션을 보면서 캐릭터의 움직임 과 영상의 변화, 소리와 음향의 효과, 문자 텍스트를 통해 몰입을 경험할 수 있다. 몰입은 '어떤 한 곳에 빠져드는 것'을 의미하는 것으로서, 흥미 요소가 극대화된 상황을 말한다. 특히, TV 시리즈물 애니메이션의 경우 몰입의 요 소가 중요하다. 유아가 애니메이션에 몰입함으로서 지속 적인 참여가 이루어지고 다음 편에 대한 기대를 하기 때 문이다[6]. 따라서 애니메이션은 재미와 교육 요소가 동 반되어야 에듀테인먼트로서의 제 기능을 수행할 수 있다.

‘뽀롱뽀롱 뽀로로’는 ‘뽀느님’, ‘뽀통령', ‘유딩들의 동 방신기’라는 수식어가 붙을 만큼 유아에게 큰 영향력을 미치고 있는 애니메이션이다. 아이코닉스 엔터테인먼트, 오콘, $\mathrm{SK}$ 브로드밴드, $\mathrm{EBS}$ 가 공동으로 제작한 $3 \mathrm{D}$ 애니메 이션으로, 유아들이 이해하고 흥미를 느낄만한 교육용 애 니메이션이 없다는 것에 초점을 맞춰 제작되었다. 2003 년 EBS 방송 당시 애니메이션의 평균 시청률을 웃도는 $5 \%$ 의 시청률을 기록하였으며[7], 출판물, 완구, DVD 시 장에서 돌풍을 일으켰다. 2003년 한국애니메이션과 한국 디지털콘텐츠 부분에서 대상을 수상하고, 2006년 Asian TV Awards 'Best Animation' 부문 노미네이트 되는 영예 를 안았다[8]. 좋은 유아용 애니메이션으로 평가받아 세 계 120 여 개국에 수출되었으며, 캐릭터 관련 시장도 연간 5,000 억원을 넘어선 성공한 애니메이션으로 꼽힌다[7]. '뽀로로'의 인기와 성공에 힙입어 현재까지 $\mathrm{EBS}$ 에서 방 송된 뽀로로 시리즈는 '뽀로로 $1,2,3,4$ ', '뽀로로의 잉글리 쉬쇼', ‘똑똑박사 에디 1,2', '요리공주 루피', '뽀로로와 노래해요 1,2 '가 있다. 이 중에서 '똑똑박사 에디'는 수학 에 초점을 맞춘 '뽀로로'의 심화학습의 성격을 지닌 애니 메이션이다. 기존의 ‘뽀로로' 친구들이 모두 등장하고 수 학 내용이 포함된 스토리가 전개되다가 어려운 문제나
궁금점이 발생되면 '에디'가 문제를 풀어주는 방식으로 이야기가 진행된다. 해설과 등장인물의 대화, 노래와 영 상의 반복 형식을 통해 유아의 이해도를 높이는 구성으 로 교육적인 효과가 뛰어나다.

수학은 인간의 생활과 밀접한 관련이 있고, 주변세계 를 이해하는데 중요한 학문이다. 수학의 중요성이 강조됨 에 따라 유아교육에서도 수학교육에 대한 관심이 증가하 고 있으며, 유아기부터 질 높은 수학교육을 제공하기 위 한 다양한 방안을 모색하고 있다[9]. 유아는 학교에 들어 가기 전부터 일상적인 경험과 주변 환경과의 상호작용을 통해 비형식적인 수학지식을 형성한다[10,11]. 유아기에 형성한 자발적인 수학지식은 이후에 교육기관에서 배우 는 형식적인 수학지식의 가교(bridge) 역할을 담당하며, 수학능력의 결정적인 기초를 담당한다[12]. 즉, 유아가 생 활 속에서 문제해결과정을 통해 배운 수학지식은 수학적 소양(mathematics literacy)능력의 토대가 된다. 유아의 수 학소양 능력을 증진시키기 위한 방안으로 미국수학교사 협의회(The National Council of Teachers of Mathematics) 에서는 2000 년에 $\ulcorner$ 학교 수학을 위한 원리와 규준 $\lrcorner$ 을 발표하였다. 이 규준집에는 5 가지 내용기준(수와 연산, 대수, 기하, 측정, 자료 분석과 확률)과 5 가지 과정기준 (문제해결하기, 추리하기와 증명하기, 의사소통하기, 연 계하기, 표상하기)이 제시되었으며, NCTM이 2006년에 발간한 $\ulcorner$ 취학전부터 8 학년까지의 수학을 위한 교육과정 핵심 요소」에는 유아기에 필요한 핵심 내용으로서 수와 연산, 기하, 측정의 내용을 중시하였다[13]. 이와 같은 맥 락으로 2013년부터 시행되는 만 3-5세 유아를 위한 누리 과정의 자연탐구영역에서는 수학 관련 목표로 “생활 속 의 여러 상황과 문제를 논리·수학적으로 이해하고 해결하 기 위한 기초능력을 기른다.”로 설정하고, ‘수학적 탐구 하기'의 내용으로 '수와 연산의 기초개념 알아보기', '공 간과 도형의 기초개념 알아보기', '기초적인 측정하기', '규칙성 이해하기', '기초적인 자료수집과 결과 나타내기' 를 제시하였다. 이는 유아기는 수와 연산, 기하, 측정 개 념이 발달하는 중요한 시기이지만, 편중된 개념보다는 다 양한 수학내용을 경험해야 함을 의미하는 것이다.

학습자의 수학문제 해결능력을 향상시키기 위해 수학 자에 의해 제안된 방법은 이야기를 활용하여 수학교육을 맥락화하는 것이다[14]. 특히, 추상적 상징 교과인 수학의 경우 스토리텔링을 통해 학습자의 경험의 유의미성과 학 습 효과를 높일 수 있다. 스토리텔링(storytelling)의 사전 적 의미는 '이야기를 들려주는 것'으로, ‘화자가 청자에 게 서사성을 가지는 이야기를 전달하는 커뮤니케이션 과 정'을 뜻한다. 즉 사람과 사물의 본질을 전달하는 과정에 서 스토리(내용 요소)가 개입되며, 이를 전달하기 위한 
활동(표현 형식)이 결합된 것이다. 애니메이션 스토리텔 링을 구현하기 위한 요소로는 캐릭터, 배경, 플롯, 주제, 영상과 음악을 들 수 있다[15,16]. 첫째, 캐릭터는 애니메 이션을 이끌어가는 중심인물이다. 스토리를 이어가는 존 재로서, 시청자를 작품 속에 몰입하도록 만드는 요소이 다. 애니메이션 캐릭터들은 자신의 성격에 맞는 외모를 지님으로서 시청자에게 강하게 어필할 수 있어야 한다. 캐릭터는 역할과 관계에 따라 주인공, 보조 주인공, 대립 자로 구분할 수 있다. 둘째, 배경은 스토리가 발생되고 전 개되는 시간과 공간을 말한다. 애니메이션은 상상력으로 탄생되는 작품이기 때문에 배경에 제약이 없다. 따라서 시간과 공간적 배경은 다양하며, 배경 속에서 캐릭터의 행위에 의해 에피소드가 진행된다. 셋째, 플롯은 서사의 흐름을 말한다. 이야기 속에서 사건이 전개되고 해결되는 과정을 의미한다. 이야기 속에는 중심서사와 보조서사가 있다. 넷째, 주제는 작품 속에 내재되어 있는 핵심적인 생 각을 말한다. 즉 이야기 속에 지배하고 있는 가장 주된 생각으로, 유아의 사고 수준과 발달적 욕구를 만족할 수 있어야 적절하다. 다섯째, 영상과 음악은 애니메이션의 효과를 높이기 위한 요소이다. 애니메이션은 이미지 변화 와 음향 및 음악의 사용으로 시청자의 감성을 자극한다. 따라서 애니메이션을 구성하고 있는 다양한 요소간의 결 합으로 시청자는 스토리텔링을 경험하게 된다.

유아용 TV 애니메이션의 수가 급증하고, 애니메이션 이 유아에게 미치는 영향력이 증가하는 시점에서 애니메 이션의 교육적인 가치와 내용을 분석하는 연구의 움직임 이 있다[17-21]. 그러나, 선행연구는 애니메이션의 순기 능을 중심으로 적절성을 비교하거나[18], 애니메이션의 특성을 중심으로 분석이 이루어졌다[19]. 또한 '유아들의 스타'로 불리우는 '뽀로로'에 관한 연구는 주로 내용을 분석[20,21]하거나, 유아교육에 끼친 의미와 한계점을 분 석한 연구[17]만이 있을 뿐이다. 애니메이션을 선정하는 가장 중요한 기준은 유아의 흥미이며[22], 유아가 가장 선호하는 애니메이션은 '뽀로로'이고, 이중에서 뽀로로, 루피, 에디의 캐릭터를 좋아하는 것으로 나타났다[23]. ‘똑똑박사 에디'는 뽀로로의 특별판으로 수학학습을 다 루고 있어서 놀이 상황 속에서 수학을 배울 수 있도록 제 작되어, '똑똑박사 에디'의 시청률은 $\mathrm{EBS}$ 의 평균 시청률 보다 높은 $6 \%$ 를 기록하였다[7]. '똑똑박사 에디'는 유아 가 좋아하는 캐릭터가 등장하여 에피소드를 진행하는 과 정에서 놀이와 교육을 연계할 수 있는 에듀테인먼트의 성격을 지낸 애니메이션이며, 유아에게 애니메이션의 내 용을 전달하기 위한 스토리텔링의 요소가 존재함에도 불 구하고, 이를 분석한 연구는 아직까지 이루어지지 않았 다. 따라서 본 연구에서는 ‘똑똑박사 에디'에 나타난 스
토리텔링 요소와 수학내용을 분석하는 것을 목적으로 한 다. 이러한 목적을 달성하기 위해 설정된 연구문제를 제 시하면 다음과 같다.

첫째, '똑똑박사 에디'에 나타난 스토리텔링의 요소는 어떠한가?

둘째, ‘똑똑박사 에디'에 나타난 수학내용은 어떠한가?

\section{2. 연구방법}

\section{1 분석 대상}

본 연구의 분석 대상은 '똑똑박사 에디 시즌 1'이다. '시즌 1'은 2010.12.1-2011.2.24에, '시즌 2'는 2012.10.12-2013.2.22에 방송되었다. 현재 '시즌 2'의 경 우에는 방송에 대한 저작권이 확보되지 않아 인터넷과 EBS 교육방송 사이트에서 다시 보기가 불가능하나, '시 즌 1'은 매주 목요일 15:45-16:00에 재방송되고 있다. 따 라서 본 연구에서는 현재 시청이 가능한 '똑똑박사 에디 시즌 1 '에 해당하는 13 편의 애니메이션을 분석대상으로 선정하였다.

\section{2 분석 절차}

작품을 분석하기에 앞서 먼저 ‘똑똑박사 에디'를 반복 시청하면서 등장인물의 대사, 행동, 상황 및 해설을 중심 으로 한글파일에 옮겨 적어 시나리오를 재구성하였다. 이 는 빠른 속도감으로 진행되는 애니메이션을 보고는 스토 리텔링 요소와 수학내용을 분석하는데 놓치는 부분이 있 을 것을 감안한 것이다. 총 13 편의 애니메이션 시나리오 는 A4 분량으로 58 페이지가 작성되었다.

재구성된 시나리오를 참고하며 동영상을 반복 시청하 면서 선행연구 $[6,15,16]$ 에서 제시한 스토리텔링의 요소를 중심으로 분석 기준을 구성하였다. 그러나 이 과정에서 분석대상의 특성에 따른 새로운 요소가 나타남으로서 노 래와 음향이라는 범주가 만들어졌다. 이를 통해 5 가지 분 류 기준이 범주화되었다. 첫째, 캐릭터로서 등장인물이 몇 명이고 누구인지, 등장인물의 성격과 역할 중심으로 분석하였다. 둘째, 시간과 공간 중심의 배경을, 셋째, 이 야기를 풀어가는 형식인 플롯을, 넷째, 이야기의 주된 핵 심 생각인 주제를, 다섯째, 노래와 음향의 기준이 설정되 었다. 또한, 시나리오와 동영상을 반복 시청하면서 선행 연구[9,24-26]에서 제시한 수학내용을 중심으로 분석 준 거를 설정하였다. 분석 기준 설정시 삼각측정법[27]을 토 대로 시나리오에 기술된 문장, 등장인물의 대화, 행동, 영 상 등 다양한 자료를 통해 수학분석 기준을 범주화하였 
다. 설정된 수학분석 기준을 제시하면 다음과 같다.

[Table 1] Analysis criterion of mathematics contents

\begin{tabular}{c|c}
\hline Category & Content \\
\hline \hline $\begin{array}{c}\text { Number } \\
\text { sense }\end{array}$ & $\begin{array}{c}\text { number meaning, quantity comparison, } \\
\text { one to one correspondence, } \\
\text { oral count(korean number), } \\
\text { object count(chinese number), } \\
\text { object count(korean number), } \\
\text { ordinal meaning, number representation, } \\
\text { place value, composition and division of } \\
\text { number, addition, subtraction, division }\end{array}$ \\
\hline Geometry & $\begin{array}{c}\text { recognition of two dimensional shapes, } \\
\text { understanding of three dimensional } \\
\text { shapes, spatial vocabulary, } \\
\text { visualization and spatial reasoning }\end{array}$ \\
\hline Measurement & $\begin{array}{c}\text { use measurement vocabulary, } \\
\text { compare and order objects, } \\
\text { measure by using nonstandard unit, } \\
\text { measure by using standard unit }\end{array}$ \\
\hline Pattern & pattern recognition, \\
pattern making
\end{tabular}

연구자에 의해 제작된 분석 기준의 적절성을 검증하기 위해서 유아교육학과 교수와 애니메이션학과 교수 각 1 인으로 구성된 전문가에게 내용 타당도를 검증 받았다. 그 결과, 애니메이션의 특성과 내용에 따라 설정된 분석 기준은 적절한 것으로 증명되었다. ‘똑똑박사 에디 시즌 1 '의 시나리오와 동영상을 반복 시청하면서 스토리텔링 의 요소는 내용분석을 중심으로 분석하고, 수학내용은 빈 도분석을 실시하였다.

\section{3. 연구결과}

\section{1 '똑똑박사 에디’ 의 스토리텔링 요소 분석}

‘똑똑박사 에디'의 스토리텔링을 구현하기 위한 분석 기준에 의해 도출된 결과를 제시하면 다음과 같다.

첫째, 시청자를 작품 속에 몰입하게 만드는 개성 있는 캐릭터가 등장한다. ‘뽀로로 시리즈’에 나오는 11 명의 등 장인물(뽀로로, 크롱, 루피, 에디, 포비, 패티, 해리, 로디, 뼤삐와 뽀뽀, 통통이)이 이야기를 만들어가며, 이들은 유 아 주변에서 흔히 볼 수 없는 동물로서 의인화하여 사람 처럼 행동한다. 일반적으로 애니메이션에서 자주 등장하 지 않는 동물을 활용하여 유아의 호기심을 유발하였다.
캐릭터의 외형은 2 등신으로 얼굴이 커서 다양한 표정을 살릴 수 있으며 외모에서 캐릭터의 성격을 짐작할 수 있 도록 묘사하였다. 유아는 등장인물의 체형과 걸음걸이 모 습이 자신과 유사하다고 느껴 친밀감을 갖게 된다. 또한, 애니메이션에서 보여주는 등장인물의 행동, 언어, 사고 양식은 전조작기 유아의 언어와 사고 수준과 비슷하다. 따라서 전조작기 유아들은 자신과 비슷한 등장인물을 좋 아하게 되고, 자기 동일시가 더욱 잘 일어날 것이다. 등장 인물의 비중도와 역할에 따라 '에디'는 주인공으로 다른 친구들은 보조 주인공으로 구분된다. 이 애니메이션의 독 특한 부분은 등장인물이 모두 유아들(동물이지만 사람처 럼 의인화하여 발달적 시기로 보아 유아의 연령에 해당 됨)이라는 점이다. 부모나 선생님의 성인이 등장하지 않 는다. 등장인물은 모두 수평적인 관계의 친구들이다. 에 피소드 속에서 어려운 문제가 발생되면 '자신보다 능력 있는 또래'인 에디에 의해 문제해결 방법을 배우게 된다. 따라서 에디는 스캐폴더(scaffolder)의 역할을 수행하며, 동등한 관계에서 이루어지는 학습의 전이력과 효과는 매 우 크다. 즉, 권위에 의한 가르침이 아니라 동등한 관계에 서 배우는 것이기 때문에 학습자는 더욱 주도적이고 적 극적인 자세를 갖게 된다.

둘째, 공간적인 배경은 하얀 눈으로 뒤덮인 숲 속 마을 을 주 배경으로 하여 집밖의 공간, 집안, 놀이터에서 에피 소드가 일어난다. 어느 조그마한 시골 마을의 겨울을 옮 겨 놓은 듯한 공간에서 이야기가 진행된다. 이 공간은 뽀 로로와 친구들의 삶의 터전이자 놀이공간이며 어른들의 간섭이 없는 자신들의 세계이다. 또한, 시간적인 배경은 겨울이며, 구체적인 시간은 알 수 없다. 다만, 에피소드가 진행되면서 시간 경과의 흐름을 알 수 있으며, 낮시간에 이야기가 이루어진다.

셋째, 스토리는 유아 주변에서 접할 수 있는 일상적이 고 평범한 이야기를 다룬다. 주로 한 가지 내용과 관련된 중심서사만 있고, 줄거리는 있으나 플롯의 구조인 발단전개-절정-결말의 형식으로 구성되어 있지 않다. 13 편의 이야기는 매회 다른 사건을 같은 방식으로 해결하는 사 건 해결형 패턴으로 이루어져 있다. 따라서 유아가 한 두 편을 보지 않아도 다음 편을 볼 때 전혀 부담이 없다. 또 한 유아의 주의집중 시간을 고려하여 1 회당 5 분 정도의 짤막한 에피소드가 진행되며, 2 편을 묶어서 15 분 내외로 방송된다.

넷째, ‘뽀롱뽀롱 뽀로로’의 심화학습 성격을 띤 애니메 이션으로 수학개념을 다루고 있다. 에피소드의 주제는 '빨간 자동차를 찾아라'(색깔), '친구들이 찾아 왔어 요'(1-10 숫자세기), ‘나는 누구일까요?'(부분 유추), ‘이 건 뭘까요?’(그림자 유추), ‘큰 빵 작은 빵'(크기, 속도), 
‘누가 무거울까요?’(무게, 길이), ‘무엇이 다를까요?’(다른 것 찾기), ‘누가 더 많을까요?’(5이하 덧셈), ‘더하기 놀 이'(10이하 덧셈), ‘공은 몇 개일까요?'(11-20 숫자 세기), ‘빼기 놀이'(5이하 뺄셈), ‘찾기 놀이'(사물 찾기, 숫자 세 기), ‘다음엔 무엇일까요?'(순서, 패턴)를 다루고 있다. 이 러한 내용 속에서 유아는 논리적인 사고력을 형성하고 수학개념을 배울 수 있다.

다섯째, 영상에 사용된 색깔은 주로 밝고 안정감 있는 원색을 이용하였다. 영상 속에서 등장인물의 행동이 나타 나며, 행동의 변화에 의해 이야기가 묘사된다. 또한 에피 소드를 전달하는 방식은 대화, 노래, 그리고 나레이션이 다. 등장인물의 대화는 주로 단문의 형태로 직접화법을 사용한다. 이는 유아의 언어수준을 고려한 적절한 방법으 로 유아가 이해하기 쉽다. 에피소드 중간에 문제해결자의 등장을 알려주는 '에디'와 관련된 노래와 문제해결 방법 이나 답과 관련된 노래가 나온다. 이 노래들은 새 노래이 거나 개사한 노래이다. 노래를 하면서 등장인물이 춤을 추기도 하고 관련 자료 영상이 이미지화되어 묘사된다. 노래는 동일한 리듬과 단어가 반복되고, 보통 한 음역대 의 음계이기 때문에 유아가 쉽게 따라 부를 수 있다. 이 러한 특징으로 인해 유아는 수학문제나 상황을 재미있게 생각하고 지루한 학습으로 받아들이지 않는다. 에피소드 의 처음과 맨 마지막 부분에는 차분한 목소리의 나레이 션이 나온다. 처음 부분은 유아의 주의를 환기시키며 이 야기에 집중할 수 있도록 상황이나 장면에 대한 이야기 가 진술되며, 마지막에는 이야기를 종결하듯이 간단한 인 사나 칭찬으로 마무리한다. 단순히 등장인물의 대화만으 로 에피소드가 진행되지 않고, 노래와 나레이션을 활용하 여 애니메이션의 재미와 교육의 효과를 극대화하는 장점 이 있다.

\section{2 '똑똑박사 에디' 의 수학내용}

'똑똑박사 에디'에 나타난 수학내용을 제시하면 다음 과 같다.

Table 2에서 보는 바와 같이 13회의 에피소드에서 총 296번의 수학적 상황이나 개념이 나타났는데, 이는 1회 당 평균 23 회의 수학개념과 상황을 접할 수 있는 수학내 용이 포함되었음을 의미한다.

‘똑똑박사 에디'에 나타난 수학개념의 하위 범주별로 는 ‘수감각' 내용은 199회(67.2\%)로 가장 많이 나타났고, '기하' 내용은 46회(15.5\%), '측정'은 26회(8.8\%), '자료 분석과 확률'은 13 회(4.4\%), '규칙성'은 12 회(4.0\%) 순으 로 나타났다. 수학의 세부내용 별로는 '수의 표상하기'가 59회(19.9\%)로 가장 많았고, '물체세기'(한자어로 물체세 기:28회, 고유어로 물체세기:13회)가 41회(13.9\%), '방향
과 위치 어휘'가 30회(10.1\%), '더하기'가 19회(6.4\%), '수량 비교하기'가 18 회(6.1\%)의 순서로 나타났다. 이러 한 결과를 종합해 보면, ‘똑똑박사 에디'에 나타난 수학 개념은 ‘수감각'에 대한 개념이 과반수 이상을 차지하여 수와 연산 관련 수학내용이 많은 비중을 차지하며, '규칙 성'과 '자료 분석과 확률' 개념은 아주 적게 내포되어 있 음을 알 수 있다.

[Table 2] Analysis criterion of mathematics contents

\begin{tabular}{|c|c|c|c|}
\hline Category & Content & \multicolumn{2}{|c|}{$\mathrm{N}(\%)$} \\
\hline \multirow{13}{*}{ (1) } & number meaning & $12(4.1)$ & \multirow{13}{*}{$199(67.2)$} \\
\hline & quantity comparison & $18(6.1)$ & \\
\hline & one to one correspondence & $12(4.1)$ & \\
\hline & $\begin{array}{c}\text { oral count } \\
\text { (korean number) }\end{array}$ & $6(2.0)$ & \\
\hline & $\begin{array}{c}\text { object count } \\
\text { (chinese number) }\end{array}$ & $28(9.5)$ & \\
\hline & $\begin{array}{c}\text { object count } \\
\text { (korean number) }\end{array}$ & $13(4.4)$ & \\
\hline & ordinal meaning & $6(2.0)$ & \\
\hline & number representation & $59(19.9)$ & \\
\hline & place value & $9(3.0)$ & \\
\hline & $\begin{array}{c}\text { composition and division } \\
\text { of number }\end{array}$ & $2(0.7)$ & \\
\hline & addition & $19(6.4)$ & \\
\hline & subtraction & $11(3.7)$ & \\
\hline & division & $4(1.4)$ & \\
\hline \multirow{4}{*}{ (2) } & $\begin{array}{l}\text { recognition of two } \\
\text { dimensional shapes }\end{array}$ & $6(2.0)$ & \multirow{4}{*}{$46(15.5)$} \\
\hline & $\begin{array}{l}\text { understanding of three } \\
\text { dimensional shapes }\end{array}$ & $2(0.7)$ & \\
\hline & spatial vocabulary & $30(10.1)$ & \\
\hline & $\begin{array}{l}\text { visualization and spatial } \\
\text { reasoning }\end{array}$ & $8(2.7)$ & \\
\hline \multirow{4}{*}{ (3) } & $\begin{array}{l}\text { use measurement } \\
\text { vocabulary }\end{array}$ & $9(3.0)$ & \multirow{4}{*}{$26(8.8)$} \\
\hline & compare and order objects & $13(4.4)$ & \\
\hline & $\begin{array}{l}\text { measure by using } \\
\text { nonstandard unit }\end{array}$ & $2(0.7)$ & \\
\hline & $\begin{array}{c}\text { measure by using standard } \\
\text { unit }\end{array}$ & $2(0.7)$ & \\
\hline \multirow{2}{*}{ (4) } & pattern recognition & $6(2.0)$ & \multirow{2}{*}{$12(4.0)$} \\
\hline & pattern making & $6(2.0)$ & \\
\hline (5) & classification & $13(4.4)$ & $13(4.4)$ \\
\hline & total & \multicolumn{2}{|c|}{$296(100.0)$} \\
\hline
\end{tabular}

(1) Number sense (2) Geometry (3) Measurement

(4) Pattern (5) Data analysis and probability 


\section{4. 논의 및 결론}

본 연구에서는 ‘똑똑박사 에디'의 스토리텔링 요소와 수학내용을 분석하는 것을 목적으로 하였다. 연구문제를 중심으로 선행연구 결과와 관련지어 논의해 보면 다음과 같다.

첫째, 시청자를 애니메이션에 몰입하게 만드는 개성 있는 11 명의 캐릭터가 등장한다. 이 캐릭터들은 주변에 서 쉽게 볼 수 없는 동물로서 사람처럼 행동하여 유아의 호기심을 이끈다. 캐릭터의 체형, 행동, 언어와 사고 수준 이 전조작기 유아의 모습과 비슷하여 자기 동일시가 쉽 게 일어날 수 있다. 에디는 문제해결자로서 주인공을, 다 른 등장인물은 보조 주인공의 역할을 한다. 성인이 등장 하지 않고 친구관계에서 교수-학습이 이루어지기 때문에 학습의 효과가 크다는 장점이 있다. 등장인물은 국내 창 작자에 의해 개발된 캐릭터이지만 글로벌화 전략에 맞게 기획되었고[28], 누구나 선호할 수 있는 보편적인 이미지 를 가지고 있어서 유아의 호기심과 흥미를 끌기에 적절 하다는 결과[16]를 뒷받침해 준다. 눈으로 뒤덮인 숲 속 마을을 주 배경으로 집밖의 공간, 집안, 놀이터에서 에피 소드가 진행된다. 겨울을 시간적 배경으로 하고 있으나, 구체적인 시간은 알 수 없다. 일반적으로 애니메이션에서 시간과 공간의 배경은 다양할 수 있으나 $[15,16]$, ‘똑똑박 사 에디'의 배경은 다양하지 않다. 유아 주변에서 경험할 수 있는 일상적이고 평범한 이야기를 주 내용으로 다루 기 때문에 다른 애니메이션보다 공간적·시간적 배경이 다양하지 않은 것으로 여겨진다. 13 편의 이야기는 사건 해결형 패턴으로 구성되고, 스토리는 있으나 플롯의 구조 는 없다. 이는 '똑똑박사 에디'의 주 연령층은 3-6세이기 때문에 주의집중 시간을 고려하여 5분 정도의 짧은 편성 으로 이루어졌기 때문으로 유추된다. 즉, 매회 시청하지 않아도 다음 편을 이해할 수 있도록 구성하고, 짧은 방송 시간으로 이야기 구조는 갖추기 어려웠을 것이다. 이러한 결과는 수많은 유아 수학그림책에는 줄거리는 있으나 이 야기 구조가 없다고 밝힌 선행연구[25]의 결과와 일맥상 통하는 결과임을 알 수 있다. 그러나 비록 '똑똑박사 에 디'의 애니메이션이 수학내용을 주 핵심으로 다루고 있 을 지라도 이야기의 구조를 갖추고 있다면, 수학학습과 더불어 유아의 문학적 소양능력 증진에도 효과가 있을 것으로 여겨진다. 에피소드에서 다양한 수학 상황 및 수 학내용을 다루므로서 유아의 논리·사고력 형성을 목적으 로 한다. 이는 만 3-5세 누리과정의 자연탐구영역에서 '수학적 탐구하기'와 '탐구하는 태도 기르기'의 내용을 내포하고 있음을 알 수 있다. 유아가 좋아하는 밝은 색상 과 안정감 있는 구도로 영상적 이미지를 표현하고, 에피
소드는 대화, 노래, 나레이션을 통해 전달된다. 유아는 언 어를 통해서 이야기를 이해하기도 하지만 시각적인 영상 을 통해서 이야기의 심상을 구성하며 이해할 수 있기 때 문에 '똑똑박사 에디'는 잘 만들어진 그림책의 요소를 가 지고 있다고 볼 수 있다. 또한, 대화에서 사용된 언어 구 조는 유아의 표현언어와 이해언어 수준에 적절하며, 반복 적인 단어와 리듬을 사용한 노래는 에피소드의 흥미를 더해준다. 애니메이션의 도입과 마무리 부분에 나오는 차 분한 목소리의 나레이션은 에피소드에 몰입하게 만드는 요인이다. 이를 통해 '똑똑박사 에디'의 영상적 이미지와 음향, 음악의 활용은 시청자의 감성을 자극하며, 흥미와 교육의 목적을 효과적으로 달성한 작품으로 볼 수 있다.

둘째, ‘똑똑박사 에디'의 에피소드에는 총 296번의 수 학상황과 수학개념이 나타났는데, 이는 유아들이 1회 방 송을 보면서 평균 23 번 정도의 수학내용을 접할 수 있음 을 의미한다.

수학개념의 하위 범주별로는 ‘수감각’의 내용이 과반 수가 넘는 비율로 나타났으며, ‘기하', ‘측정', ‘자료 분석 과 확률', '규칙성'의 순으로 나타났다. 즉, 수와 연산의 내용을 가장 많이 다루고 있었고, ‘공간과 도형'의 개념 은 일부분, '측정'은 소수, '통계'와 '대수'개념은 아주 극 소수로 다루고 있었다. 이는 유아용 CD-ROM의 수학내 용을 분석한 선행연구[29,30]결과와도 일치하는 결과이 다. 또한, 유아 수학그램책에서 다루고 있는 수학개념은 수감각의 개념이 가장 많고, 공간 및 도형, 측정, 규칙성, 자료 정리 및 결과 나타내기의 순으로 결과가 도출된 선 행연구[25]의 분석에도 부합되는 결과임을 알 수 있다. 유아기에는 수와 연산, 기하, 측정 개념이 가장 중요하지 만[26], 제한된 수학내용보다는 폭넓고 다양한 수학내용 이 깊이 있게 다루어질 필요가 있다[11]. 따라서 '똑똑박 사 에디'에 나온 수학개념은 유아의 발달에 적절한 수학 내용이지만, 좀 더 다양하며 깊이 있는 내용이 포함된다 면 유아의 수학적 소양능력(mathematics literacy)을 형성 하는데 기여할 수 있을 것으로 사료된다.

본 연구는 아이들에게 인기있고 교육적인 가치를 담은 ‘똑똑박사 에디'의 스토리텔링 요소와 수학내용을 분석 하여 에듀테인먼트로서의 가치를 밝힌 측면에서 의의가 있을 것이다. 또한, 수학을 일상생활 속에서 유아가 겪을 수 있는 문제상황으로 접근하여 수학의 가치 및 유용성 을 느낄 수 있는 계기를 제시해 주었다. 따라서 교사는 유아와 함께 ‘똑똑박사 에디'를 시청하고 그 속에 담긴 수학문제를 역할놀이 상황으로 접근해 본다면, 유아는 수 학개념과 과정을 쉽게 이해할 수 있으며 수학적 소양능 력을 형성하는 계기가 될 것이다. 이러한 본 논문의 의의 및 활용도의 가치에도 불구하고, 방송 저작권이 확보되지 
않아 다시보기가 불가능한 작품(시즌 2)은 연구대상에서 제외했기 때문에 후속연구에서는 이 자료를 확보한 연구 와 시즌 1 과 시즌 2 의 내용을 비교·분석해 보는 연구가 이루어지길 기대해 본다.

\section{References}

[1] S. H. Heo, “An Effect of engagement-inducing production style in animation to influence on comprehension of children", Unpublished master's thesis, Duksung Women's University, 2010.

[2] www.ebs.co.kr.

[3] K. S. Park, "Study on storytelling strategy of korean animation", The Korean Journal of Animation, Vol.3, No.2, pp.38-59, 2007.

[4] H. J. Kim, "Study of english edutainment animation for preschoolers", Cartoon \& Animation Studies, No.24, pp.107-133, 2011.

[5] Y. M. Lee, "A Study on the character storytelling structure of early childhood educational animations", Unpublished doctoral dissertation, Sejong University, 2007.

[6] B. P. Baek, "Research on creating an effective storytelling strategy for child edutainment animations", Unpublished master's thesis, Kyungsung University, 2010.

[7] www.media.daum.net.

[8] www.iconix.co.kr.

[9] NCTM, "Principles and standards for school mathematics. Reston, VA: The National Council of Teachers of Mathematics, Inc. 2000.

[10] R. Balfanz, H. P. Ginsburg, C. Greens, "The big math for little kids early childhood mathematics program", Teaching Children Mathematics, Vol.9, No.5, pp.264-268, 2003.

[11] D. H. Clements, "Mathematics in the preschool", Teaching Children Mathematics, Vol.7, No.5, pp.270-275, 2001.

[12] J. Y. Kim, "The Development of evaluation tools for young children's math ability based on content standards of NCTM", Unpublished doctoral dissertation, Wonkwang University, 2004.

[13] K. O. Nah, K. H. Kim, "Mathematics education for young children", Hakjisa, 2012.

[14] Y. C. Cho, "A Study on the design and effectiveness analysis of mathematics teaching-learning plan through a storytelling model", Unpublished master's thesis, Pusan National University, 2012.

[15] J. Y. Kim, "A Study on embodited animation storytelling of 'A Fairy and A Woodcutter", Unpublished master's thesis, Dankook University, 2008.

[16] J. Y. Cho, "Focused on TV series a an analysis by components of animation character storyteller", Unpublished master's thesis, Hansung University, 2012.

[17] E. J. Kim, H. N. Im, "Exploration of infant's educational significances and critical points in 'Pororo' TV animation", The Journal for Children's Media, Vol.10, No.2, pp.163-185, 2011.

[18] J. W. Shin, B. M. Jeong, S. H. Hong, "An Impact of animation produced for children on early childhood education", Journal of Korea Design Knowledge, Vol.24, 377-386, 2012.

[19] G. I. Lee, "A Study on characteristic of the edutainment animation: Focusing on TV series animation", Unpublished master's thesis, Soonchunhyang University, 2007.

[20] D. H. Jung, O. K. Jung, H. J. Lee, “An Analysis of friendship factors and the process of forming friendship in TV edutainment animation", The Journal for Children's Media, Vol.9, No.1, pp.333-356, 2010.

[21] H. Y. Jung, S. M. Bang, "An Analysis of early childhood character education trends as portrayed in the TV animation series 'The little penguin Pororo'", Korean Journal of Early Childhood Education, Vol.32, No.1, pp.159-181, 2012.

[22] E. J. Kang, E. J. Hyun, "A Survey on early childhood teachers' use and perception of animation: Focus on disney animation", Korean Journal of Early Childhood Education, Vol.21, No.2, pp.299-318, 2001.

[23] Y. J. Ko, M. J. Kim, “Animation character preference according to age and gender of children", Journal of the Korea Contents Association, Vol.12, No.3, pp.470-479, 2012.

DOI: http://dx.doi.org/10.5392/JKCA.2012.12.03.470

[24] Ministry of Education, Science and Technology, $\ulcorner 3$ to 5 Nuri Curriculum $\lrcorner, 2013$.

[25] J. E. Yu, Y. S. Kim "An Analysis of math picture books for children in relation to an integrated curriculum approach", The Journal for Children's Media, Vol.8, No.2, pp.295-321, 2009.

[26] NCTM, "Curriculum focal points for prekindergarten through grade 8 mathematics: A quest for coherence. Reston, VA: The National Council of Teachers of Mathematics, Inc, 2006. 
[27] M. Q. Patton, "Qualitative evaluation and research methods(2nd ed.). Newbury Park, CA: Sage, 1990.

[28] D. I. Choi, "A Study of successful strategies through case analyses of korean animated movies", Journal of the Korean Society for Computer Game, No.13, pp.92-97, 2008.

[29] H. S. Kim, "The Contents and the developmental appropreative of math education CD-ROM titles for young children", Unpublished master's thesis, Duksung Women's University, 2001.

[30] S. E. Lee, "A Study on the contents and quality of CD-ROM title of mathematics education for early childhood", Unpublished master's thesis, Ewha Woman's University, 2001.

\section{김 지 영(Ji-Young Kim)}

[정회원]

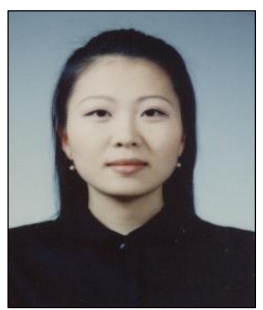

- 2002년 2월 : 원광대학교 대학원 유아교육과 (문학석사)

- 2005년 2월 : 원광대학교 대학원 유아교육과 (문학박사)

- 2005년 3월 현재 : 호남대학교 유아교육과 교수

<관심분야>

언어교육, 미디어교육 